\title{
(国) QUEEN'S UNIVERSITY BELFAST

\section{Mobilising the Next Generation of Stated-Preference Studies: the Association of Access Device with Choice Behaviour and Data Quality}

Vass, C. M., \& Boeri, M. (2021). Mobilising the Next Generation of Stated-Preference Studies: the Association of Access Device with Choice Behaviour and Data Quality. The Patient - Patient-Centered Outcomes Research, 14(1), 55-63. https://doi.org/10.1007/s40271-020-00484-x

\section{Published in:}

The Patient - Patient-Centered Outcomes Research

\section{Document Version:}

Peer reviewed version

Queen's University Belfast - Research Portal:

Link to publication record in Queen's University Belfast Research Portal

\section{Publisher rights}

Copyright 2020, Springer Nature Switzerland AG

This work is made available online in accordance with the publisher's policies. Please refer to any applicable terms of use of the publisher.

\section{General rights}

Copyright for the publications made accessible via the Queen's University Belfast Research Portal is retained by the author(s) and / or other copyright owners and it is a condition of accessing these publications that users recognise and abide by the legal requirements associated with these rights.

Take down policy

The Research Portal is Queen's institutional repository that provides access to Queen's research output. Every effort has been made to ensure that content in the Research Portal does not infringe any person's rights, or applicable UK laws. If you discover content in the Research Portal that you believe breaches copyright or violates any law, please contact openaccess@qub.ac.uk. 


\title{
Mobilizing the next generation of stated preference studies: the association of access device with choice behaviour and data quality
}

\author{
Authors: Caroline M VASS ${ }^{\mathrm{ab}}$; Marco BOERI ${ }^{\mathrm{c}}$ \\ ${ }^{a}$ RTI Health Solutions, Manchester, UK \\ ${ }^{\mathrm{b}}$ The University of Manchester, Manchester, UK \\ ${ }^{\mathrm{c} R T I}$ Health Solutions, Belfast, UK
}

Corresponding author: Caroline Vass, RTI Health Solutions, The Pavilion, Towers Business Park, Wilmslow Road, Didsbury, Manchester, United Kingdom; cvass@ @rti.org; +44 161-446-1732 (institution URL: https://www.rtihs.org/)

Caroline Vass ORCID: 0000-0002-6385-2812

Marco Boeri ORCID: 0000- 0001-7346-2132

Target journal: The Patient

Word count: $\sim 3,750$

Number of manuscript pages: TBC

Number of Tables and Figures: 3 tables, 1 figures

Running title: Access device and stated preferences

Keywords: Discrete Choice Experiment, Stated Preferences, Access Device, Healthcare

Financial support: Caroline Vass was in receipt of a National Institute for Health Research (NIHR) School for Primary Care Research (SPCR) Ph.D studentship between October 2011 and 2014. The views expressed are those of the author(s) and not necessarily those of the NIHR or the Department of Health and Social Care.

Ethics: This paper was prepared in compliance with ethical standards. Ethical approval for the study was granted by the University of Manchester's Research Ethics Committee.

Declaration: CV and MB have no conflicts of interests.

Acknowledgements: We are grateful to Professors Katherine Payne, Dan Rigby, and Stephen Campbell of the University of Manchester for their feedback during the development of the stated preference survey.

Data availability: The datasets generated during and/or analysed during the current study are still undergoing further analyses and are unavailable. 


\section{ABSTRACT}

Background: There is a rising interest in the use of stated preference methods to understand the values individuals place on health and health care. Literature reviews show stated preference studies are increasingly administered online, potentially maximising respondent access and allowing for randomisation, skips and forced choices to prevent illogical answers. Online respondents can often choose which device they use to complete a survey: personal computer (PC), laptop, tablet, or smartphone. These devices have different screen sizes and modes of data entry, so to avoid differences in measurement errors, frequently respondents are asked to complete the surveys on a PC or large tablet despite evidence that handheld devices are increasingly used for internet browsing. As yet, it is unknown if or how the device used to access the survey affects responses and/or the subsequent valuations derived.

Method: This study uses data from a discrete choice experiment (DCE) administered online. The analysis explores differences in key outcomes such as completion rates, engagement with the survey materials, respondent characteristics, response time, failure of an internal validity test, and health care preferences for 1) handheld devices and 2) PC users. Preferences were analysed using a fully correlated random parameter logit model.

Results: One-thousand respondents completed the survey. The most popular access device were PCs $(\mathrm{n}=785)$ including Windows $(\mathrm{n}=705)$ and Macbooks $(\mathrm{n}=69)$. Two-hundred and fifteen respondents accessed the survey on a handheld device. Most outcomes related to survey behaviour including failure of a dominance check, 'flat-lining', self-reported attribute non-attendance (ANA), or respondent rated task difficulty did not differ by device type $(\mathrm{p}>0.100)$. Respondents accessing the survey using a PC were generally quicker (median time to completion 14.5 minutes compared to 16 minutes for those using handheld devices) and were significantly less likely to speed through a webpage. Although there was evidence of preference intensity (taste) or variability (scale) heterogeneity across respondents in the sample, it was not driven by the access device.

Conclusion: Overall, we find that neither preferences nor choice behaviour is associated with the type of access device, as long as they are presented with question formats that are easy to use on small touchscreens. Health preference researchers should optimise preference instruments for a range of devices, and encourage respondents to complete the surveys using their preferred device. However, we suggest that the information about access device should be checked and included when reporting results. 


\section{KEY POINTS FOR DECISION MAKERS}

- This study found most survey behaviours and question responses were unaffected by the type of device used to access the survey.

- There was also no evidence to suggest preference intensity (taste) or variability (scale) was associated with the type of device used to complete the discrete choice experiment.

- Health preference researchers should ensure their surveys are optimised for computers, tablets and mobile phones, and encourage respondents to complete the survey using a device of their choice.

- The information about access device and its potential impacts should be discussed when reporting results. 


\section{Introduction}

Survey-based stated preference methods are increasingly used to elicit and quantify preferences for health states and health care goods or services [1,2]. Discrete choice experiments (DCEs) are among the many methods currently available and used to elicit stated preferences [3]. Systematic reviews of healthcare DCEs have shown the number of surveys administered online has increased over time. Only 11\% of DCEs were web-based between 2001 and 2008 whereas between 2013 and 2017 approximately $57 \%$ of healthcare DCEs were administered online [4,5]. There are obvious technical advantages to conducting preference research online such as the option to incorporate skip-logics, include adaptive experimental designs, and incorporate interactive information or videos [6,7]. There are also advantages in terms of resources: it is often easier and less expensive to recruit and reimburse respondents with online panels, and data collection is instantaneous with no need for manual entry [8].

A handful of studies have compared paper-based and online stated-preference surveys using both computer-assisted personal interviews (CAPI) and internet panel providers [9-11]. Watson et al., (2019) [9] found CAPI surveys to have high response rates and high representativeness, and Ryan et al., (2020) [10] also found online internet panels to be superior to mail-based surveys in terms of response rates. Determann et al., (2017) [11] compared online panel with mail-based administration and found few differences between the choices; the rank order and relative importance of attributes were similar across both samples, and interaction terms depicting the survey mode were not statistically significant at the $1 \%$ level. The authors identified (1) a smaller proportion of online sample were satisfied with the number of choice sets and (2) the online sample had a lower response time (this measure relied on selfreport by mail-based respondents). The studies did not compare responses across access device; however, Watson et al., (2019) [9] stated that one panel provider would "offer panelists the ability to take part in on [sic] any device, including smartphones" (p.838) and Determann and colleagues [11] suggest "Future studies might therefore want to focus on the effects of completing a DCE on different digital devices, such as laptops, tablets, and smartphones" (p. 959).

Although the evidence indicates that online surveys are comparable or perhaps superior to mail-out surveys, it is currently unclear if online users are equivalent across devices e.g., smart phones, tablets or personal computers (PCs). Information on this topic is likely to become crucial as the use of handheld devices (i.e., smartphones, tablets) is growing at a fast pace, passing from $16 \%$ of the whole internet traffic worldwide in 2013, to over 53\% in 2019 [12]. Discordance in responses across devices could be due to various reasons which may lead to bias. Some devices have small screens or operating systems that are inferior and inhibit readability or functionality of the survey [13]. There are other characteristics: the use of a cursor and ability to highlight text with a PC, compared with rapid scrolling and zooming available on touch screen tablets and phones [14]. Device connection may also not be 
random across the sample resulting in selection biases [15]. Furthermore, research has shown older adults have been slow to adopt mobile technology and continue to access the internet traditional desktop PCs [16].

Several computer science and sociology studies have looked at how the use of smartphone in accessing surveys online impacted data quality and bias in on computer-assisted survey research generally $[13,17-$ 19]. However, the presence of these issues and biases have not been explored as extensively in preference analysis. Results from the first and, to our knowledge, only study looking at the impact of the use of mobile devices impacted on data quality and choice behaviour in a web-based DCE are reported in Liebe et al., (2015) [20] who elicited preferences for sources of renewable energy. Similar to studies in the more general survey literature from computer and social science [17,21], Liebe and colleagues [20] found that respondents who accessed the survey with a mobile device needed more time to answer the survey compared to computer users and that there was a negative correlation between screen size and time to completion. In the DCE, no significant difference in scale and no difference in the selection of the status quo option were identified across subsamples. However, the authors found differences in price sensitivity, resulting in higher willingness to pay for respondents who participated from a desktop or laptop. Overall Liebe et al., (2015) [20] conclude that using mobile devices is not detrimental to survey quality.

The results of Liebe et al., (2015) [20] provide some indication of the potential effect, or lack of, between access device and stated preferences in a study eliciting preferences for renewable energy production; however, the results may not be generalisable to a health context where the interventions being appraised may be less familiar and the trade-offs/survey content more abstract. In health preference research specifically, Hartman \& Craig (2019) [22] considered device and connection type on reported health utilities (EQ-5D-5L) in an online survey to over 15,000 respondents. The authors found that the quality of responses was largely unaffected by the type of device used and that allowing mobile devices increased the diversity of respondents and the likelihood of achieving representativeness in the sample. Surveys eliciting health utilities are not typically as complex as those incorporating a stated preference instrument, and do not require respondents to make tradeoffs. There are no stated preference studies exploring the effect of access device on preferences in a DCE exploring preferences for health or healthcare.

If health stated preference studies continue to be administered online, it is important to understand if preference survey responses, and particularly the valuations derived, are robust to the respondent's connection device, and that the use of handheld devices does not impact on data quality and choice behaviour. Figure 1 summaries the key features of handheld devices and their potential relation to outcomes of a stated preference study. 
This study aims to explore this issue using data from a large DCE administered to 1,000 female members of the public to understand if device type used was associated with various parameters including: i) survey participation (drop-out rate); ii) respondents' sociodemographic characteristics; iii) response time and attention; iv) self-reported understanding; v) failure rate of an internal validity test; vi) self-reported attribute non-attendance; vii) preference results. The availability of an existing dataset made exploring the relationship between quality of the stated-preference data and access device possible.

\section{Methods}

Details of the design and results of the DCE survey are reported elsewhere (see [23,24]). The sample included female members of the public aged over 18 years old. Quotas were used to over-sample women of or just before screening age. All respondents were invited to complete the study via email invitation from an online internet panel provider. Background information about the intervention was provided using text and a short video clip. The DCE comprised 11 choice sets (10 experimentally-designed scenarios and one to test for internal validity). At the end of the choice-sets, respondents were asked socio-demographic questions as well as self-reported ease of choice making, confidence in decision and attribute attendance.

The survey was programmed using Sawtooth software (version 8) which captured the respondents' device type, browser, and operating system, as well as the time spent on each webpage and the point of drop-out (e.g., quotas full, respondent exited, or respondent completed). Survey creation and preliminary testing was conducted using a PC housing the Sawtooth software. This version of the Sawtooth software included updates which enhanced survey viewing on small devices (less than 600 pixels wide). Prior to launching the survey, pre-test interviews and in-depth qualitative interviews were conducted with Apple iPads. Compatibility with other devices was not formally explored. Research Now (currently known as Dynata) recruited participants for the study. Approval for the study was obtained from The University of Manchester's Research Ethics Committee (Ref. 13178).

\subsection{Analysis}

Devices were classified systematically and in consultation with an information technology (IT) specialist. However, some categories were unidentified, for example, Linux devices were assumed to be PCs rather than tablets or phones. For transparency, classifications are presented in Appendix A.

\subsubsection{Descriptive characteristics and survey behaviour}


To explore whether the device used to complete the DCE survey instrument was associated with a selfselection bias, descriptive statistics were produced for the sample and subsamples of PC and handheld device users. Differences between the groups were tested using a Fisher's exact test. In addition, 'behaviour' outcomes such being identified as a speeders $(=1$ if an the respondents spent less than 2 seconds on any webpage); task difficulty ( $=1$ if the respondent rated this hard [4] or very hard [5] on a scale of 1-5); failure rate of the internal validity test (=1 if failed); and self-reported attribute nonattendance ( $=1$ if respondent reported that they focused on one or two attributes to make their choice) were also investigated. Finally, before looking at patient preferences, other decision heuristics such as always choosing the opt-out of 'No Screening' or always opting in, were examined.

\subsubsection{Preference Data Analysis}

Conditional-multinomial logit (MNL) models were used as a benchmark to compare different model specifications. The MNL was also used to explore whether reweighting the data using entropy balancing to ensure that the handheld device and PC groups were identical on observed characteristics impacted results (see Appendix B). Since the data analysis was performed to examine whether the use of different devices (i.e., handheld device or PC) impacts on key parameters, before pooling data from users of different devices together, it is important to test for differences. Following the idea proposed by [25] we used a two-step approach: first a null hypothesis of equality of the coefficient estimates across samples was tested against an alternative hypothesis that the coefficient estimates are different. Should the first null hypothesis accepted, then differences in scale (which reflect differences in preference variability) are explored.

The analysis of the observed choices is grounded in the conventional random utility theory framework [26] as implemented by MNL modelling [27]. In this context, respondents were assumed to choose the alternative that maximized their utility. After identifying the best utility specification, to account for the cross-section/panel nature of the data [28] and accommodate for heterogeneity within the data, final analyses were conducted using random-parameters logit (RPL) models.

The RPL model still assumes that, for each individual, the choice probability is a logit, but the sample probability requires integrating over a distribution of preferences specified by the analyst. Generally, most studies in health assume a normal distribution for all attribute levels, but this is not a constraint of the model; other distributions can be used [29]. Once a functional form has been determined for the distribution of individual preferences, it is possible to specify the RPL model in a manner consistent with either independence of preference intensities (by identifying only its diagonal values) or correlation (by allowing for nonzero off-diagonal values). The latter model assumes and estimates full covariance among coefficients, allowing for unexplained preference heterogeneity as well as all sources of correlation, including the correlation that is induced by scale heterogeneity [30,31]. 
Although most existing applications of the RPL model do not include correlations across randomly distributed parameters in RPL model, we opted for this specification as it improved how the model fitted the data due to evidence of unexplained scale and preference heterogeneity.

The parameters for each attribute (detection rate, risk of unnecessary follow-up, and cost of screening) were assumed to have a normal distribution. As the RPL model has no closed form [32], the models were estimated using maximum simulated likelihood with 500 Halton draws. Finally, in each model specification a dummy coded variable $=1$ for handheld device or $=0$ for a PC was interacted with all the model parameters to test for systematic differences in preferences between each subgroup. A Wald test of the joint significance of the interaction terms indicated whether preferences between the two groups were statistically systematically different.

Data were analysed using Stata 16 [33] and the Apollo Choice Modelling package [34] in R 4.0 (https://cran.r-project.org/).

\section{Results}

One thousand five-hundred and nighty-two respondents started the survey. Of those accessing the survey, most of the sample ( $\mathrm{n}=1,270 ; 79.8 \%)$ accessed the survey using a PC and $322(20.2 \%)$ used a handheld device. Respondents accessing the survey on a handheld device were more likely to complete the survey; $61.8 \%$ (CI: 59.1-61.6) of PC users completed the survey compared with 66.8\% (CI: 61.671.9) using tablets or phones.

A total of 1,000 completed the survey in its entirety. All further analyses were conducted with this sample which was split between PC users $(n=785)$ and handheld devices $(n=215)$. Devices were classified into one of these two subgroups according to Appendix A. The most popular PC devices were Microsoft Windows ( $n=705)$ or Apple MacIntosh ( $n=69)$ operating system. Of those using handheld devices, most used an Apple iPad $(n=102)$ or Android device $(n=68)$.

\subsection{Respondent Characteristics}

For key sociodemographic characteristics, the two samples differed $(\mathrm{p}<0.05)$ on age, education, mammogram experience and reports of breast cancer in their family (see Table 1).

For handheld device users, the most common age bracket was 35 to 44 years old (32.1\%) whereas the most common age bracket for PC users was 50 years or older (32.4\%). The women who accessed via PC were more likely to have had a mammogram (45.9\% compared with $34.9 \%$ ) whereas those using handheld devices were more likely to report breast cancer in their family (41.4\% compared with $33.8 \%$ ). 
The samples differed on numeracy $(\mathrm{p}=0.072)$, with $23.1 \%$ of PC users answering all three questions correctly, compared with $18.1 \%$ of respondents on a handheld device.

\subsection{Survey Behaviours}

Most other survey-related behaviours, were robust to device type (see Table 2). One exemption was 'speeding': respondents who were using a PC were more likely $(\mathrm{p}=0.035)$ to 'speed' through a webpage (taking less than two seconds). Respondents accessing the survey using a PC generally completed the survey quicker, taking on average (median) 14.5 minutes compared with 16 minutes for those using handheld devices. There were no statistically significant differences ( $>0.100)$ between the groups for the other outcomes assessed.

\subsection{Preference Analysis}

MNL models suggested preference estimates were unaffected by weighting the data to ensure balance on individual characteristics between the handheld device and PC groups (see Appendix B, Table B1). Subsequent analyses were therefore conducted using unweighted data. The test adapted from Swait and Louviere [25] suggested the data from respondents using handheld devices and respondents using PC could be pooled for the analysis as, on average, data from the two sub-samples resulted in the same preference intensity (taste) and variability (scale). Furthermore, the RPL models with and without interactions demonstrated that heterogeneity, although present in the data, was not explained by the type of device used to access the survey. All coefficient estimates were statistically significant and aligned with a priori expectations; respondents preferred higher detection and lower risk and cost (see Table $3)$.

\section{Discussion}

This is one of the first studies to investigate how respondents' access device can affect data quality and choices behaviour in a health stated preference study. The DCE survey appeared to be well understood by respondents with almost two-thirds of respondents reporting the survey to be 'very easy' or 'easy', and all coefficients aligning with a priori expectations and demonstrating statistically significance. Similarly, the correlations between the attributes matched a priori expectations. Overall, the respondent's device did not appear to affect either data quality, choice behaviours or their stated preferences. Although there is evidence of differences in both preference intensity (taste) and variability (scale) across the sample, not explained by observed data.

The study finds parallels with existing research into the effect of device type of respondents' valuations. For example, Hartman \& Craig (2019) [22] found consistencies in the EQ-5D-5L utility 
values across devices. However, the authors also found handheld device users were more likely to drop-out whereas we found a higher proportion of PC users left before completing the survey.

Hartman \& Craig (2019) [22] also reported higher levels of logical inconsistencies among tablet users, and although our study does not differentiate between tablets and phone users, we found no statistical difference $(\mathrm{p}=0.424)$ in failure of the internal validity test. Other literature considering the effect of access device in web surveys more generally have also found consistency in responses across different devices $[35,36]$.

The only statistically significant difference in survey behaviours identified in this study related to 'speeding' through a webpage (i.e., spending less than 2 seconds on any single page). This finding coupled with higher average (mean and median) times to completion suggests smaller screens may take longer perhaps because it is harder to navigate the survey on small screen. This aligns with the results of other studies investigating the effect of access device on general survey behaviour; for example, Couper \& Peterson (2017) [21] and Wells et al., (2014) [17] also found mobile respondents tended to take longer. However, as response time does not appear to be associated with choice behaviour or data quality, we would recommend health preference researchers optimise their survey for all devices. This may be particularly important going forward as there is evidence that mobile phones are increasingly used to access the internet, overtaking PCs in late 2019 as the most popular browsing device in both the United Kingdom (UK) and United States (US) [12]. For researchers conducting studies in developing countries, web access is most nations is almost entirely through the mobile internet [37] and thus excluding phone or tablet users may bias the sample and/or results.

This study uses data from a single large survey to a sample of women so the results are limited in their generalizability to other settings. Health preference researchers should be cognizant of other issues which may become more or less prominent with different devices in different context. Studies $[36,38]$ have also found PC users are more likely to have potentially distracting 'third parties' which maybe more prevalent and more problematic in some instances where privacy is important. The study also incorporated three attributes whereas reviews of DCEs have shown most studies in health use between four and six [5]. In addition to the generalisability limitation, in this study, device type was also inferred by the operating system, browser and personal communication with an IT expert. However, some Android devices or iPad devices may have been used with attachable keyboards in a PC-style set-up. We could not confidently distinguish between Android devices (mobile phones, tablets) and therefore classified all as handheld. Similarly, we did not have information about the screen size of the different devices.

This study was not designed to detect differences in the device type and so some tests for differences may be underpowered. Future studies may have a more balanced sample given recent rises in the 
proportion of tablet users. Similarly, studies designed specifically to investigate the effect of device type may consider recording other key variables which could inhibit functionality such as screen size or connection type. Also adjusting the number attributes to understand if there is a maximum for mobile devices could be a useful investigation for health preference researchers. Furthermore, future research should look at how specific adaptation to mobile device (for example allowing to swipe and tap small portion of the DCE at a time, instead of visualize the full DCE in one screen) could impact on choice behaviour and data quality. Finally, randomisation of respondents would allow investigations of the causal effect of device type, eliminating selection biases, but would be challenging to implement in a large sample.

\section{Conclusion}

Preference data from the DCE completed by respondents accessing with handheld devices and respondents accessing from PCs were not systematically different. Although we did not find any evidence for preference intensity (taste) or variability (scale) heterogeneity driven by the type of device used to complete the survey, the results from the fully correlated RPL model suggest the presence of unexplained scale and preference heterogeneity across respondents. Our results suggest most survey behaviours (flat lining, self-reported ANA, self-reported task difficulty) are unaffected by type of device used to access the online survey. As there was little evidence in this study to suggest access device affected important survey outcomes, we recommend health preference researchers ensure their surveys are optimised for all types of devices. Allowing respondents to complete preference surveys on their preferred device negates the need to restrict access which could, in some contexts, skew the sample. We also do not find evidence that accessing our survey with different types of devices could impact on either the preference data quality. However, there is not enough empirical evidence to generalize this finding. It is important for future health preference assessment studies to report data on how respondents accessed their survey and to use the Swait and Louviere [25] test or similar procedures to ensure that data captured from different devices can be pooled together, and to check for, and report, differences across access device. Further research should also consider randomizing respondents to different devices and to different survey styles (i.e., more or less tailored to handheld device) to understand if, and how, tailoring stated preference survey programming for compatibility across technologies affects preferences or the valuations derived.

\section{References}

1. Louviere J, Hensher D, Swait J. Stated choice methods: analysis and application [Internet]. Cambridge University Press; 2000. Available from: http://books.google.com/books?id=nk8bpTjutPQC\&pgis=1 
2. Smith RD, Sach TH. Contingent valuation: what needs to be done? Heal Econ policy law [Internet]. 2010 [cited 2014 Aug 13];5:91-111. Available from: http://www.ncbi.nlm.nih.gov/pubmed/19706221

3. Soekhai V, Whichello C, Levitan B, Veldwijk J, Pinto CA, Donkers B, et al. Methods for exploring and eliciting patient preferences in the medical product lifecycle: a literature review. Drug Discov. Today. 2019. p. 1324-31.

4. Clark M, Determann D, Petrou S, Moro D, de Bekker-Grob EW. Discrete choice experiments in health economics: a review of the literature. Pharmacoeconomics [Internet]. 2014;32:883-902. Available from: http://onlinelibrary.wiley.com/doi/10.1002/hec.1697/full

5. Soekhai V, de Bekker-Grob EW, Ellis AR, Vass CM. Discrete Choice Experiments in Health Economics: Past, Present and Future. Pharmacoeconomics. 2019. p. 201-26.

6. Vass CM, Davison NJ, Vander Stichele G, Payne K. A Picture is Worth a Thousand Words: The Role of Survey Training Materials in Stated-Preference Studies. Patient [Internet]. Springer International Publishing; 2020;13:163-73. Available from: https://doi.org/10.1007/s40271-019-00391-w

7. Lim SL, Yang JC, Ehrisman J, Havrilesky LJ, Reed SD. Are Videos or Text Better for Describing Attributes in StatedPreference Surveys? Patient. 2020;

8. Callegaro M, Lozar Manfreda K, Vehovar V. Web survey methodology. Sage. London, UK; 2015.

9. Watson V, Porteous T, Bolt T, Ryan M. Mode and Frame Matter: Assessing the Impact of Survey Mode and Sample Frame in Choice Experiments. Med Decis Mak. 2019;0272989X1987103.

10. Ryan M, Mentzakis E, Matheson C, Bond C. Survey modes comparison in contingent valuation: Internet panels and mail surveys. Heal Econ (United Kingdom). 2020;29:234-42.

11. Determann D, Lambooij MS, Steyerberg EW, de Bekker-Grob EW, de Wit GA. Impact of Survey Administration Mode on the Results of a Health-Related Discrete Choice Experiment: Online and Paper Comparison. Value Heal. 2017;20:95360.

12. Statcounter. GlobalStats [Internet]. 2020. [cited 2020 Jul 10]. Available from: https://gs.statcounter.com/

13. Lugtig P, Toepoel V. The Use of PCs, Smartphones, and Tablets in a Probability-Based Panel Survey: Effects on Survey Measurement Error. Soc Sci Comput Rev. 2016;34:78-94.

14. Antoun C, Couper MP, Conrad FG. Effects of Mobile versus PC Web on Survey Response Quality [Internet]. Public Opin. Q. 2017. p. 280-306. Available from: https://academic.oup.com/poq/article-abstract/81/S1/280/3091905

15. Fuchs M, Busse B. The Coverage Bias of Mobile Web Surveys Across European Countries. Int J Internet Sci. 2009;4:21-33.

16. Vaportzis E, Clausen MG, Gow AJ. Older adults perceptions of technology and barriers to interacting with tablet computers: A focus group study. Front Psychol. 2017;8.

17. Wells T, Bailey JT, Link MW. Comparison of Smartphone and Online Computer Survey Administration. Soc Sci Comput Rev. 2014;32:238-55. 
18. Struminskaya B, Weyandt K, Bosnjak M. The effects of questionnaire completion using mobile devices on data quality. Evidence from a probability-based general population panel. Methods, Data, Anal [Internet]. 2015;9:261-92. Available from: https://mda.gesis.org/index.php/mda/article/view/2015.014

19. de Bruijne M, Wijnant A. Mobile Response in Web Panels. Soc Sci Comput Rev. 2014;32:728-42.

20. Liebe U, Glenk K, Oehlmann M, Meyerhoff J. Does the use of mobile devices (tablets and smartphones) affect survey quality and choice behaviour in web surveys? J Choice Model. 2015;14:17-31.

21. Couper MP, Peterson GJ. Why Do Web Surveys Take Longer on Smartphones? Soc Sci Comput Rev. 2017;35:357-77.

22. Hartman JD, Craig BM. Does Device or Connection Type Affect Health Preferences in Online Surveys? Patient. 2019;12:639-50.

23. Vass CM, Rigby D, Payne K. Investigating the Heterogeneity in Women's Preferences for Breast Screening: Does the Communication of Risk Matter? Value Heal. 2018;21:219-28.

24. Vass C, Rigby D, Payne K. "I Was Trying to Do the Maths": Exploring the Impact of Risk Communication in Discrete Choice Experiments. Patient. 2019;12:113-23.

25. Swait J, Louviere J. The Role of the Scale Parameter in the Estimation and Comparison of Multinomial Logit Models. J Mark Res [Internet]. 1993;30:305-14. Available from:

http://search.ebscohost.com/login.aspx?direct=true \&db=bth\&AN=9312020140\&site=ehost-live

26. Thurstone L. A law of comparative judgment. Psychol Rev. 1927;34:273-86.

27. McFadden D. Conditional logit analysis of qualitative choice behaviour. Zarembka P, editor. Front. Econom. New York: Academic Press INC; 1974. p. 105-42.

28. Hauber AB, González JM, Groothuis-Oudshoorn CGM, Prior T, Marshall DA, Cunningham C, et al. Statistical Methods for the Analysis of Discrete Choice Experiments: A Report of the ISPOR Conjoint Analysis Good Research Practices Task Force. Value Heal [Internet]. 2016;19:300-15. Available from: http://dx.doi.org/10.1016/j.jval.2016.04.004

29. Hensher D, Greene W. The mixed logit model: the state of practice. Transport [Internet]. 2003;30:133-76. Available from: http://link.springer.com/article/10.1023/A:1022558715350

30. Hess S, Rose JM. Can scale and coefficient heterogeneity be separated in random coefficients models? Transportation (Amst). 2012;39:1225-39.

31. Hess S, Train K. Correlation and scale in mixed logit models. J Choice Model. 2017;23:1-8.

32. Train K. Discrete choice methods with simulation [Internet]. 2nd ed. Cambridge University Press; 2009 [cited 2015 May 25]. Available from:

http://books.google.com/books?hl=en\&lr=\&id=4yHaAgAAQBAJ\&oi=fnd\&pg=PR7\&dq=Discrete+Choice+Methods+with+ Simulation\&ots=eDZ9Jbk-ay\&sig=CFowMO5CMgul5kMzcvx4ory9hBg

33. StataCorp. Stata Statistical Software: Release 16. College Station, TX: StataCorp LP. 2019; 
34. Hess S, Palma D. Apollo: A flexible, powerful and customisable freeware package for choice model estimation and application. J Choice Model. 2019;32.

35. Mavletova A, Couper MP. Sensitive topics in PC web and mobile web surveys: Is there a difference? Surv Res Methods. 2013;7:191-205.

36. Toninelli D, Revilla M. Smartphones vs PCs: Does the device affect the web survey experience and the measurement error for sensitive topics? A replication of the mavletova \& Couper's 2013 experiment. Surv Res Methods. 2016;10:153-69.

37. Glushkova S, Belotserkovich D, Morgunova N, Yuzhakova Y. The role of smartphones and the Internet in developing countries. Espacios. 2019;40.

38. Revilla M, Toninelli D, Ochoa C. PCs versus Smartphones in answering web surveys: does the device make a difference? Surv Pract. 2016;9:1-6. 
Table 1. Sample characteristics by device type

\begin{tabular}{|c|c|c|c|c|}
\hline Outcome & Handheld Device & PC & Overall & Fisher's test \\
\hline & $\mathrm{n}=215$ & $\mathrm{n}=785$ & $\mathrm{n}=1000$ & \\
\hline & $\mathrm{n}(\%)$ & $\mathrm{n}(\%)$ & $\mathrm{n}(\%)$ & $P$ value \\
\hline \multicolumn{4}{|l|}{ Age } & \multirow{6}{*}{0.006} \\
\hline $18-24$ & $21(9.8 \%)$ & $79(10.1 \%)$ & $100(10.0 \%)$ & \\
\hline $25-34$ & $27(12.6 \%)$ & $73(9.3 \%)$ & $100(10.0 \%)$ & \\
\hline $35-44$ & $69(32.1 \%)$ & $181(23.1 \%)$ & $250(25.0 \%)$ & \\
\hline $45-49$ & $52(24.2 \%)$ & $198(25.2 \%)$ & $250(25.0 \%)$ & \\
\hline $50+$ & $46(21.4 \%)$ & $254(32.4 \%)$ & $300(30.0 \%)$ & \\
\hline \multicolumn{4}{|l|}{ Highest education } & \multirow{8}{*}{0.048} \\
\hline No formal qualifications & $8(3.7 \%)$ & $31(3.9 \%)$ & $39(3.9 \%)$ & \\
\hline 1-4 O-levels/GCSEs & $17(7.9 \%)$ & $92(11.7 \%)$ & $109(10.9 \%)$ & \\
\hline 5+ O-levels/GCSEs & $24(11.2 \%)$ & $85(10.8 \%)$ & $109(10.9 \%)$ & \\
\hline NVQs / A-levels/AS-levels & $65(30.2 \%)$ & $241(30.7 \%)$ & $306(30.6 \%)$ & \\
\hline Undergraduate degree & $55(25.6 \%)$ & $215(27.4 \%)$ & $270(27.0 \%)$ & \\
\hline Master's degree & $20(9.3 \%)$ & $79(10.1 \%)$ & $99(9.9 \%)$ & \\
\hline Other & $26(12.1 \%)$ & $42(5.4 \%)$ & $68(6.8 \%)$ & \\
\hline \multicolumn{4}{|l|}{ Employment status } & \multirow{9}{*}{0.421} \\
\hline Employed full-time & $79(36.7 \%)$ & $262(33.4 \%)$ & $341(34.1 \%)$ & \\
\hline Employed part-time/ temping & $45(20.9 \%)$ & $164(20.9 \%)$ & $209(20.9 \%)$ & \\
\hline Self-employed & $7(3.3 \%)$ & $50(6.4 \%)$ & $57(5.7 \%)$ & \\
\hline Unemployed/ laid-off & $5(2.3 \%)$ & $25(3.2 \%)$ & $30(3.0 \%)$ & \\
\hline Retired & $23(10.7 \%)$ & $110(14.0 \%)$ & $133(13.3 \%)$ & \\
\hline Looking after a home/family & $35(16.3 \%)$ & $101(12.9 \%)$ & $136(13.6 \%)$ & \\
\hline Student & $14(6.5 \%)$ & $43(5.5 \%)$ & $57(5.7 \%)$ & \\
\hline Long-term sickness & $7(3.3 \%)$ & $30(3.8 \%)$ & $37(3.7 \%)$ & \\
\hline Ethnicity ${ }^{\mathrm{a}}$ & & & & \multirow{3}{*}{0.169} \\
\hline White & $193(89.8 \%)$ & $723(92.1 \%)$ & $916(91.6 \%)$ & \\
\hline Not white & $22(10.2 \%)$ & $62(7.9 \%)$ & $84(8.4 \%)$ & \\
\hline \multicolumn{4}{|l|}{ Religion $^{\mathrm{a}}$} & \multirow{4}{*}{0.618} \\
\hline None & $85(39.5 \%)$ & $292(37.2 \%)$ & $377(37.7 \%)$ & \\
\hline Christian & $118(54.9 \%)$ & $435(55.4 \%)$ & $553(55.3 \%)$ & \\
\hline Other & $12(5.6 \%)$ & $58(7.4 \%)$ & $70(7.0 \%)$ & \\
\hline Has children & $141(65.6 \%)$ & $492(62.7 \%)$ & $633(63.3 \%)$ & 0.242 \\
\hline Had a mammogram & $75(34.9 \%)$ & $360(45.9 \%)$ & $435(43.5 \%)$ & 0.002 \\
\hline Had a follow-up for breast cancer & $35(16.3 \%)$ & $112(14.3 \%)$ & $147(14.7 \%)$ & 0.262 \\
\hline $\begin{array}{l}\text { Had cases of breast cancer in the } \\
\text { family }\end{array}$ & $89(41.4 \%)$ & $265(33.8 \%)$ & $354(35.4 \%)$ & 0.024 \\
\hline $\begin{array}{l}\text { Answered all three numeracy } \\
\text { correct }\end{array}$ & $39(18.1 \%)$ & $181(23.1 \%)$ & $220(22.0 \%)$ & 0.072 \\
\hline
\end{tabular}

${ }^{a}$ Variables collapsed for simplicity 
Table 2. Survey behaviours by device type

\begin{tabular}{|c|c|c|c|c|}
\hline Outcome & Handheld Device & $\mathbf{P C}$ & Overall & Fisher's test \\
\hline & $\mathrm{n}=215$ & $\mathrm{n}=785$ & $\mathrm{n}=1000$ & \\
\hline & $\mathrm{n}(\%)$ & $\mathrm{n}(\%)$ & $\mathrm{n}(\%)$ & $P$ value \\
\hline Failed the internal validity test & $17(7.9 \%)$ & $68(8.7 \%)$ & $85(8.5 \%)$ & 0.424 \\
\hline $\begin{array}{l}\text { Reported ANA to at least one } \\
\text { attribute }\end{array}$ & $99(46.0 \%)$ & $350(44.6 \%)$ & $449(44.9 \%)$ & 0.380 \\
\hline Self-reported task difficulty (1-5) & & & & \multirow{6}{*}{0.555} \\
\hline 1 (very easy) & $73(34.0 \%)$ & $269(34.3 \%)$ & $342(34.2 \%)$ & \\
\hline 2 & $58(27.0 \%)$ & $239(30.4 \%)$ & $297(29.7 \%)$ & \\
\hline $\begin{array}{l}3 \text { (neither difficult } \\
\text { nor easy) }\end{array}$ & $64(29.8 \%)$ & $191(24.3 \%)$ & $255(25.5 \%)$ & \\
\hline 4 & $18(8.4 \%)$ & $78(9.9 \%)$ & $96(9.6 \%)$ & \\
\hline 5 (very difficult) & $2(0.9 \%)$ & $8(1.0 \%)$ & $10(1.0 \%)$ & \\
\hline Select the optout always & $9(4.2 \%)$ & $33(4.2 \%)$ & $42(4.2 \%)$ & 0.584 \\
\hline $\begin{array}{l}\text { Select the optout sometimes } \\
\text { (including those who always select } \\
\text { it) }\end{array}$ & $47(21.9 \%)$ & $188(23.9 \%)$ & $235(23.5 \%)$ & 0.294 \\
\hline $\begin{array}{l}\text { Select the optout sometimes but not } \\
\text { always }\end{array}$ & $38(17.7 \%)$ & $155(19.7 \%)$ & $193(19.3 \%)$ & 0.282 \\
\hline Never select the optout & $168(78.1 \%)$ & $597(76.1 \%)$ & $765(76.5 \%)$ & 0.294 \\
\hline Respondent answered quickly ${ }^{\mathrm{a}}$ & $88(40.9 \%)$ & $378(48.2 \%)$ & $466(46.6 \%)$ & 0.035 \\
\hline \multirow[t]{2}{*}{ Response time (seconds) } & Handheld Device & $\mathrm{PC}$ & Overall & $\mathrm{T}$ test \\
\hline & $\mathrm{n}=215$ & $\mathrm{n}=785$ & $\mathrm{n}=1000$ & \\
\hline Mean (SD) & $2180(7400)$ & $1619(5750)$ & $1740(6142)$ & 0.236 \\
\hline Median & 958 & 869 & 888 & \\
\hline Min & 198 & 129 & 129 & \\
\hline Max & 89446 & 93185 & 93185 & \\
\hline
\end{tabular}

ANA $=$ attribute non-attendance.

a 'Quick' defined as $<2$ seconds on any webpage. 
Table 3. Preference analysis: Fully-correlated RPL ( $N=1000)$

\begin{tabular}{|l|l|l|l|}
\hline & Coefficient estimate & SE & P-value \\
\hline ASC (none) & & & \\
\hline Detect a cancer & -6.978 & 0.375 & $<0.001$ \\
\hline Risk of unnecessary follow-up & 0.182 & 0.012 & $<0.001$ \\
\hline Cost of screening & -0.100 & 0.007 & $<0.001$ \\
\hline
\end{tabular}

$\mathrm{ASC}=$ alternative specific constant. 
Figure 1. Features of Handheld Devices and Key Parameters Investigated

Survey participation (drop-out rate)
Sociodemographic characteristics
Response time and attention
Self-reported understanding
Failure rate of an internal validity test
Self-reported attribute non-attendance
Preference results
Preferences


Appendix A: Classification of device types
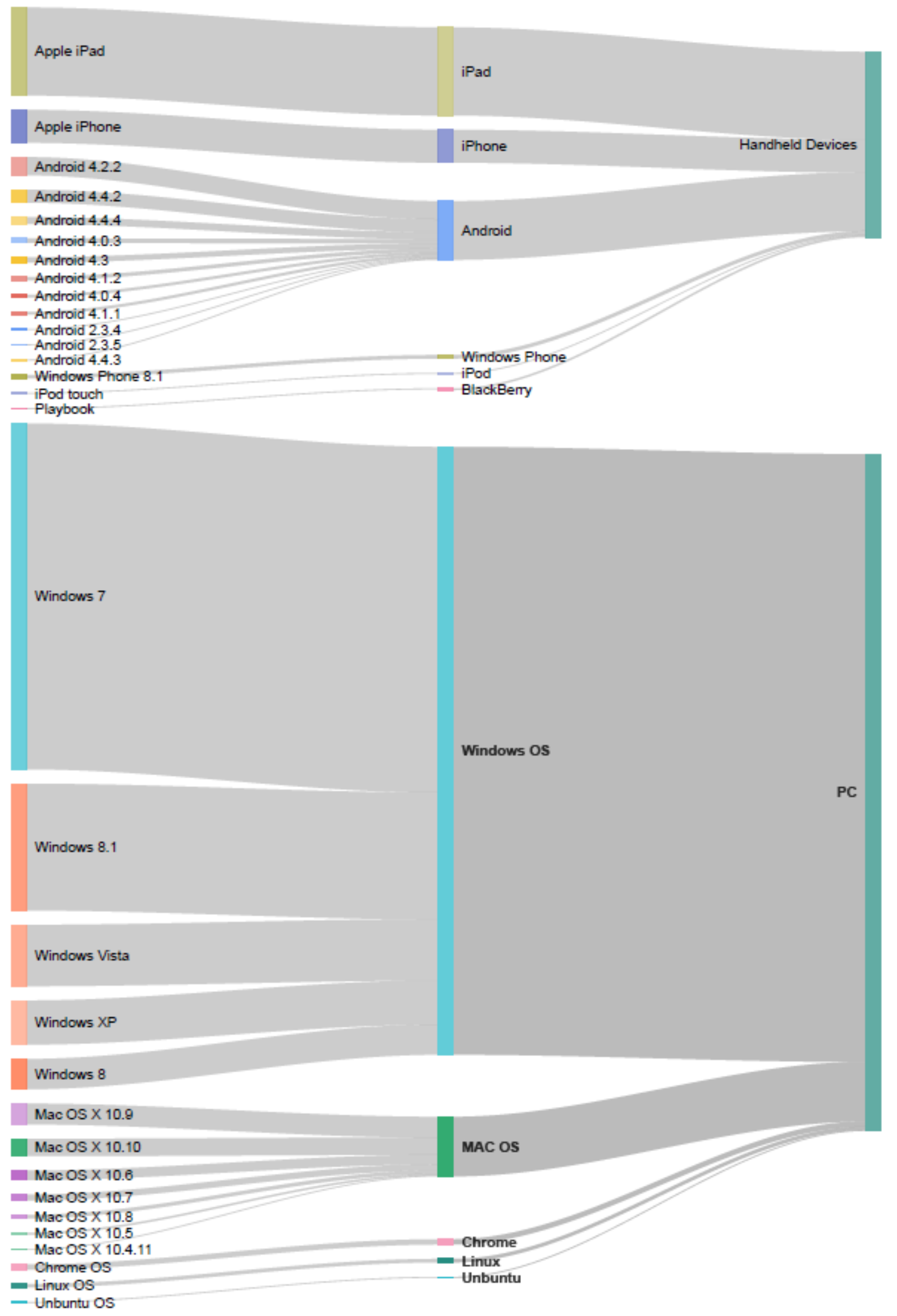
We examined whether reweighting the data using entropy balancing impacted results. Entropy balancing generates individual weights for individuals in the PC user group such that the first and second moments of the distributions of the individual characteristics are identical to those of the handheld device group [1]. Unlike propensity score matching/weighting, entropy balancing ensures perfect balance on characteristics as weights are chosen so that balance constraints hold exactly. Entropy balancing was implemented using the Stata [2] package 'ebalance' [3]. Table B1 shows that preference weights are almost identical in the unweighted and weighted samples. This is perhaps not surprising given the small levels of imbalance in the unweighted sample (shown in Table 1).

Table B1. MNL models: Unweighted and weighted samples

\begin{tabular}{|c|c|c|c|c|}
\hline & \multicolumn{2}{|l|}{ Unweighted sample } & \multicolumn{2}{|l|}{ Weighted sample } \\
\hline & Coefficient estimate & SE & Coefficient estimate & SE \\
\hline ASC (none) & $-1.421 * * *$ & $(0.06)$ & $-1.338 * * *$ & $(0.07)$ \\
\hline Detect a cancer & $0.080 * * *$ & $(0.00)$ & $0.083 * * *$ & $(0.00)$ \\
\hline Risk of unnecessary follow-up & $-0.041 * * *$ & $(0.00)$ & $-0.040 * * *$ & $(0.00)$ \\
\hline Cost of screening & $-0.095 * * *$ & $(0.01)$ & $-0.090 * * *$ & $(0.01)$ \\
\hline
\end{tabular}

$\mathrm{ASC}=$ alternative specific constant; $* \mathrm{p}<0.05 ; * * \mathrm{p}<0.01 ; * * * \mathrm{p}<0.001$.

Individual characteristics included age, education, employment, ethnicity, religion, having children, experience of mammography, experience of screening follow-up, experience of cancer in the family, and numeracy.

\section{References}

1. Hainmueller J. Entropy balancing for causal effects: A multivariate reweighting method to produce balanced samples in observational studies. Pol Anal. 2012; 1:25-46.

2. StataCorp v.16. Stata data analysis and statistical Software. Special Edition Release. 2019.

3. Hainmueller J, Xu Y. Ebalance: A Stata package for entropy balancing. Journ Stat Soft. 2013 Sep 1;54(7). 